\title{
COMPARACIÓN DE MÉTODOS DE EXTRACCIÓN DE ADN DE Giardia spp. MEDIDOS POR PCR CONVENCIONAL
}

\author{
Kathia Tarqui-Terrones ${ }^{1,2, a, b}$, Juana I. Silva-Molina ${ }^{1,2, a}$, María Beltrán-Fabián ${ }^{1, a}$, Silvia Zevallos-Vara ${ }^{3, a}$, \\ Egma Mayta-Huatuco $2, \mathrm{a}, \mathrm{c}$
}

\begin{abstract}
RESUMEN
Objetivos. Comparar diferentes métodos de extracción de ADN a partir de quistes y trofozoítos de Giardia spp. mediante la técnica de reacción en cadena de la polimerasa (PCR) convencional. Materiales y métodos. Se aislaron quistes de Giardia spp. a partir de 65 muestras coprológicas procedentes de hospitales de referencia nacional, obteniéndose una carga promedio de $5 \times 10^{4}$ parásitos. Asimismo, se cultivaron trofozoítos de Giardia intestinalis (ATCC $\left(30957^{\mathrm{TM}}\right.$ ) obteniéndose una carga parasitaria de $5 \times 10^{6}$. Se compararon once métodos de extracción para quistes y seis para trofozoítos. La concentración y pureza del ADN extraído se determinó por espectrofotometría y el rendimiento de la extracción se evaluó mediante la amplificación de los genes beta giardina (bg) y glutamato deshidrogenasa (gdh) por PCR semi-anidada. Resultados. Se observó que el método I mostró la mayor concentración de ADN a partir de quistes $(12,24 \mathrm{ng} / \mu \mathrm{L})$, pureza $(1,4)$ y mejor rendimiento $(100 \%$ amplificación bg, $60 \% \mathrm{gdh})$ en comparación con los otros métodos evaluados. En el caso de los trofozoítos el método que no tuvo pretratamientos presentó la mayor concentración de ADN, pureza y rendimiento $(26,56 \mathrm{ng} / \mu \mathrm{L} ; 1,85 ; 100 \%$ amplificación bg y gdh). Conclusiones. Los pretratamientos mecánicos, de choque térmico y enzimáticos son necesarios para la ruptura de la pared quística de Giardia spp., siendo el marcador molecular bg de mayor rendimiento para detección de ADN de quistes. Los trofozoítos no requieren pretratamientos para lograr resultados satisfactorios. Se cuenta con una metodología reproducible para la extracción de ADN de Giardia spp. a partir de cualquier estadio evolutivo.
\end{abstract}

Palabras clave: Giardia; ADN; Reacción en Cadena de la Polimerasa; Trofozoítos (fuente: DeCS BIREME).

\section{COMPARISON OF METHODS OF DNA EXTRACTION FROM Giardia spp. MEASURED BY CONVENTIONAL PCR}

\begin{abstract}
Objectives. To compare different methods of DNA extraction from cysts and trophozoites of Giardia spp. using the conventional polymerase chain reaction (PCR) technique. Materials and Methods. Cysts of Giardia spp. were isolated from 65 coprological samples from national reference hospitals, obtaining an average load of $5 \times 10^{4}$ parasites. In addition, Giardia intestinalis trophozoites (ATCC ${ }^{\circledR} 30957^{\mathrm{TM}}$ ) were cultured obtaining a $5 \times 10^{6}$ parasitic load. Eleven extraction methods for cysts and six for trophozoites were compared. The concentration and purity of the extracted DNA were determined by spectrophotometry and the extraction yield was assessed by amplification of the ß-giardin (bg) and glutamate dehydrogenase (gdh) genes with a semi nested PCR assay. Results. It was observed that method 1 showed the highest concentration of DNA from cysts $(12.24 \mathrm{ng} / \mathrm{\mu L}$ ), purity (1.4) and best performance (bg: $100 \%$ amplification; gdh: $60 \%$ amplification) compared to the other methods evaluated. In the case of trophozoites, the method without pre treatment showed the highest level of DNA concentration, purity, and yield $(26.56 \mathrm{ng} / \mu \mathrm{L} ; 1.85 ; 100 \%$ amplification of bg and gdh, respectively). Conclusions. Mechanical, thermal shock, and enzymatic pre-treatments are necessary for the rupture of the cystic wall of Giardia spp. making it the highest-yielding bg molecular marker for detecting cyst DNA. Trophozoites do not require pre-treatment to achieve satisfactory results. A reproducible methodology for the extraction of DNA from Giardia spp. from any evolutionary stage is available.
\end{abstract}

Keywords: Giardia; DNA; Polymerase Chain Reactions; Trofozoites (source: MeSH NLM).

\footnotetext{
Centro Nacional de Salud Pública, Instituto Nacional de Salud. Lima, Perú

Universidad Nacional Mayor de San Marcos. Lima, Perú.

Hospital Nacional Sergio E. Bernales. Lima, Perú.

Bióloga; ${ }^{\mathrm{b}}$ magíster en Epidemiología; ${ }^{\mathrm{c}}$ doctora en Ciencias

Recibido: 31/12/2018 Aprobado: 17/07/2019 En línea: 26/08/2019
}

Citar como: Tarqui-Terrones K, Silva-Molina JI, Beltrán-Fabián M, Zevallos-Vara S, Mayta-Huatuco E. Comparación de métodos de extracción de ADN de Giardia spp. medidos por PCR convencional. Rev Peru Med Exp Salud Publica. 2019;36(3):423-32. doi:http://dx.doi.org/10.17843/rpmesp.2019.363.4160. 


\section{INTRODUCCIÓN}

Giardia spp. es uno de los principales parásitos que afecta al ser humano (1). Millones de personas alrededor del mundo padecen de anemia y desnutrición crónica a causa de este protozoario entérico ${ }^{(2)}$, y en Perú se estima una prevalencia entre 15 y $18 \%{ }^{(3)}$. Presenta dos estadios evolutivos claramente diferenciados que se adaptan a distintas condiciones ambientales; el trofozoíto, forma invasiva responsable de los síntomas de la enfermedad; y el quiste, forma de resistencia, responsable de la transmisión de huésped a huésped ${ }^{(4)}$.

El uso de técnicas moleculares en los estudios de parasitología como la reacción en cadena de la polimerasa (PCR) muestran una elevada sensibilidad para la detección de casos con bajos niveles de infección y para discriminar entre variantes genéticas de los aislados; en el caso de la giardiasis se ha reportado una sensibilidad de $80 \%$ a $100 \%{ }^{(5)}$ y especificidad del $100 \%$ al ser comparado con ADN procedente de muestras humanas con otros parásitos como Blastocystis hominis, Chilomastix mesnilii, y Entamoeba coli ${ }^{(4,6)}$.

Los métodos de extracción tradicionales in house utilizan solventes orgánicos para separar a las proteínas y lípidos del ADN a fin de aislarlo por precipitación con etanol. Estos métodos requieren preparar soluciones y la extracción puede durar varias horas ${ }^{(7)}$. Los métodos comerciales son más rápidos ${ }^{(8)}$, están basados en membrana de sílica, facilitando con ello la adsorción de la molécula de ADN a la membrana cargada positivamente para lograr el aislamiento de ADN integro con calidad y cantidad adecuadas, libre de contaminantes e inhibidores ${ }^{(9)}$; garantizando el diagnóstico molecular, disminuyendo falsos negativos, y mejorando su sensibilidad.

En Perú, existe escasa información sobre métodos de extracción de ADN de parásitos como Giardia spp., lo que limita el conocimiento de la tipificación molecular de especies nativas circulantes, así como el estudio de la resistencia molecular frente a drogas. La selección del método de extracción es un paso fundamental en las técnicas moleculares y depende del organismo bajo estudio y del tipo de muestra; en el caso de Giardia spp. el quiste del parásito es el estadio más utilizado ${ }^{(4)}$. Cabe resaltar que, su pared quística es gruesa, está compuesta por proteínas e hidratos de carbono, lo que le confiere resistencia a la degradación química, siendo necesaria la aplicación de diferentes pretratamientos como choque térmico, degradación enzimática, efecto mecánico o la combinación de estos para lograr su ruptura o degradación ${ }^{(10,11)}$. Por lo tanto, es importante evaluar su utilidad e implicancia en la calidad de ADN y en el éxito de la amplificación por PCR.

Con el propósito de optimizar un método de extracción de ADN reproducible, óptimo y sencillo para la detección de Giardia spp. en cualquier estadio evolutivo se compararon diferentes métodos de extracción de ADN a partir de quistes

\section{MENSAJES CLAVE}

Motivación para realizar el estudio. Se evaluaron diferentes métodos de extracción de ADN a partir de quistes y trofozoítos de Giardia spp. ante la necesidad de implementar metodologías más sensibles para el diagnóstico y tipificación molecular de la giardiasis.

Principales hallazgos. Los resultados indican que para optimizar la extracción de ADN parasitario a partir de quistes es necesario realizar pretratamientos mecánicos, enzimáticos y de choque térmico, para aumentar la concentración de ADN y detección molecular del agente.

Implicancias. Este trabajo sirve de base para realizar estudios de caracterización y resistencia molecular de Giardia spp. en el país ya que es posible extraer $\mathrm{ADN}$ de la forma invasiva e infectante del parásito.

y trofozoítos del parásito mediante PCR semianidado usando dos marcadores moleculares, gen glutamato deshidrogenasa (gdh) y betagiardina (bg).

\section{MATERIALES Y MÉTODOS}

\section{DISEÑO DE ESTUDIO}

Se realizó un estudio de tipo descriptivo con diseño observacional.

\section{MUESTRAS FECALES}

Se trabajó con 65 muestras fecales humanas positivas a Giardia spp. procedentes de tres hospitales de referencia nacional en Lima-Perú (Hospital Arzobispo Loayza, Hospital Cayetano Heredia y Hospital Nacional Sergio E. Bernales), obtenidas por muestreo de tipo no probabilístico intencionado durante el periodo de agosto 2017 a febrero de 2018. El criterio de inclusión para las muestras fue la presencia del parásito Giardia spp. en una carga parasitaria promedio de dos a cinco quistes por campo microscópico; asimismo, no deberían contener ningún fijador parasitológico. Las muestras fueron transportadas en un cooler y confirmadas por microscopía en el Laboratorio de Referencia Nacional de Enteroparásitos del Instituto Nacional de Salud, mediante examen parasitológico directo, luego fueron almacenadas a $4^{\circ} \mathrm{C}$ hasta su proceso.

Los quistes fueron purificados y concentrados por el método de gradiente de sucrosa de dos fases ${ }^{(12-14)}$. Las muestras de heces fueron emulsionadas con agua destilada y filtradas con gasa; previamente a un tubo de vidrio $16 \times 100 \mathrm{~mm}$ se colocó $3 \mathrm{~mL}$ de sucrosa $0,85 \mathrm{M}$, al que se le agregó igual volumen de la suspensión fecal y se centrifugó a 2300 rpm por cinco minutos; luego, se recuperó la fase sucrosa-agua y se realizaron tres lavados con agua destilada centrifugando a las mismas revoluciones descritas. Posteriormente, se preparó un tubo con gradiente de sucrosa $0,85 \mathrm{M}$ a $0,4 \mathrm{M}$ al que se le agregó cuidadosamente el sedimento 
lavado y se centrifugó a 2300 rpm durante diez minutos a $4{ }^{\circ} \mathrm{C}$. Finalmente, los quistes purificados colectados de la interfase se lavaron nuevamente para eliminar la sucrosa y fueron resuspendidos en agua destilada siendo almacenados a $-20^{\circ} \mathrm{C}$ hasta ser procesados.

\section{MUESTRAS DE CULTIVO}

Se trabajó con un cultivo in vitro de Giardia intestinalis (ATCC $\AA 30957^{\mathrm{TM}}$ ) obtenido de fase exponencial en medio TYI-S-33 modificado (Tripticasa, extracto de levadura, hierro y suero) enriquecido con suero bovino fetal (10\%) basados en el método descrito por Keister ${ }^{(15)}$, el cual permite un desarrollo adecuado del parásito.
Para lograr el desprendimiento de los mismos de la superficie del tubo, a los cultivos se les sometió a un baño de hielo por diez minutos, posteriormente diez inversiones y frotación entre las palmas de las manos, siendo luego centrifugados a $2500 \mathrm{rpm}$ por cinco minutos a $4{ }^{\circ} \mathrm{C}$. Asimismo, para estimar la carga parasitaria se empleó el recuento en cámara Neubauer. Las muestras se guardaron a $-20^{\circ} \mathrm{C}$ hasta ser procesadas.

\section{EXTRACCIÓN DE ADN DE QUISTES}

EI ADN de los quistes fue extraído usando 11 métodos de extracción como se observa en la Tabla 1. Cada método tiene un pretratamiento o la combinación de estos. Los pretratamientos fueron físicos: choque térmico, con ciclos

Tabla 1. Métodos de extracción de ADN de Giardia spp. a partir de quistes.

\begin{tabular}{|c|c|}
\hline Métodos & Descripción \\
\hline Método I & $\begin{array}{l}\text { Pretratamiento mecánico 1: Uso de perlas de vidrio. } \\
\text { Pretratamiento enzimático 1: Incubar con el búfer de lisis } \mathrm{E}(100 \mathrm{mM} \text { Tris- } \mathrm{HCl}, 200 \mathrm{mM} \mathrm{NaCl}, 100 \mathrm{mM} \text { EDTA, } 2 \% \\
\mathrm{SDS}, 1 \mathrm{mM} \text { mercaptoetanol) y búfer GTP }(5 \mathrm{mM} \text { tiocianato de guanidina, } 50 \mathrm{mM} \text { tris- } \mathrm{HCl}, 50 \% \text { fenol). } \\
\left.\text { Pretratamiento choque térmico } 1:\left(100^{\circ} \mathrm{C}--20^{\circ} \mathrm{C}\right) \text { por } 30 \text { minutos / una hora ( } 1 \text { ciclo }\right) \text { y cinco minutos ( } 1 \text { ciclo). } \\
\text { Extracción: Kit comercial Stool DNA Isolation de Norgen. }\end{array}$ \\
\hline Método II & $\begin{array}{l}\text { Pretratamiento enzimático 1: Incubar con el búfer de lisis } \mathrm{E} \text { ( } 100 \mathrm{mM} \text { tris- } \mathrm{HCl}, 200 \mathrm{mM} \mathrm{NaCl}, 1 \%, 100 \mathrm{mM} \text { EDTA, } \\
2 \% \text { SDS, } 1 \mathrm{mM} \text { mercaptoetanol) y búfer GTP ( } 5 \mathrm{mM} \text { tiocianato de guanidina, } 50 \mathrm{mM} \text { tris- } \mathrm{HCl}, 50 \% \text { fenol). } \\
\text { Extracción: Kit comercial Stool DNA Isolation de Norgen. }\end{array}$ \\
\hline Método III (18) & $\begin{array}{l}\text { Pretratamiento mecánico 1: Uso de perlas de vidrio. } \\
\text { Pretratamiento choque térmico 2: ( } 100^{\circ} \mathrm{C} \text { - nitrógeno líquido) por tres minutos repetidos en seis ciclos. } \\
\text { Extracción: Kit comercial Stool DNA Isolation de Norgen. }\end{array}$ \\
\hline Método IV & $\begin{array}{l}\text { Pretratamiento choque térmico } 2:\left(100{ }^{\circ} \mathrm{C} \text { - nitrógeno líquido) por tres minutos repetidos en seis ciclos. }\right. \\
\text { Pretratamiento enzimático 1: Incubar con el búfer de lisis } \mathrm{E}(100 \mathrm{mM} \text { tris- } \mathrm{HCl}, 200 \mathrm{mM} \mathrm{NaCl}, 100 \mathrm{mM} \text { EDTA, } 2 \% \\
\mathrm{SDS}, 1 \mathrm{mM} \text { Mercaptoetanol) - búfer GTP ( } 5 \mathrm{mM} \text { tiocianato de guanidina, } 50 \mathrm{mM} \text { tris-HCl, } 50 \% \text { fenol). } \\
\text { Pretratamiento enzimático 2: Incubar con proteinasa K toda la noche. } \\
\text { Extracción: Kit comercial Stool DNA Isolation de Norgen. }\end{array}$ \\
\hline Método V & $\begin{array}{l}\text { Pretratamiento choque térmico 2: ( } 100{ }^{\circ} \mathrm{C} \text { - nitrógeno líquido) por tres minutos repetidos en seis ciclos. } \\
\text { Pretratamiento enzimático 3: Incubar con el búfer tritón }(50 \mathrm{mM} \text { tris- } \mathrm{HCl}, 150 \mathrm{mM} \mathrm{NaCl}, 1 \% \text { tritón X-100, } 5 \mathrm{mM} \\
\text { EDTA) - búfer GTP ( } 5 \mathrm{mM} \text { tiocianato de guanidina, } 50 \mathrm{mM} \text { tris- } \mathrm{HCl}, 50 \% \text { fenol). } \\
\text { Extracción: Kit comercial Stool DNA Isolation de Norgen. }\end{array}$ \\
\hline Método VI (19) & $\begin{array}{l}\text { Pretratamiento choque térmico } 2:\left(100{ }^{\circ} \mathrm{C} \text { - nitrógeno líquido) por dos minutos repetidos en tres ciclos. }\right. \\
\text { Pretratamiento enzimático } 2 \text { : Incubar con proteinasa } \mathrm{K} 56^{\circ} \mathrm{C} \text { toda la noche. } \\
\text { Extracción: Kit comercial PureLink Genomic DNA para tejidos de Invitrogen. }\end{array}$ \\
\hline Método VII (20) & $\begin{array}{l}\text { Pretratamiento enzimático 4: Incubar con búfer de lisis } 3(1 \mathrm{M} \text { tris-HCl, } 1 \% \text { tritón } \mathrm{X}-100,0,5 \mathrm{M} \text { EDTA, } 2 \% \mathrm{SDS}, 0,2 \\
\mathrm{N} \mathrm{NaOH}, 1 \mathrm{mM} \text { mercaptoetanol) y búfer } \mathrm{GTP}(5 \mathrm{mM} \text { tiocianato de guanidina, } 50 \mathrm{mM} \text { tris-HCl, } 50 \% \text { fenol). } \\
\left.\text { Pretratamiento choque térmico } 1:\left(100{ }^{\circ} \mathrm{C} \mathrm{a}-20^{\circ} \mathrm{C}\right) \text { por } 30 \text { minutos/1hora (1 ciclo) y cinco minutos ( } 1 \mathrm{ciclo}\right) \text {. } \\
\text { Extracción: In house, fenol - cloroformo - alcohol isoamílico. }\end{array}$ \\
\hline Método VIII (21) & $\begin{array}{l}\text { Pretratamiento mecánico 1: Uso de perlas de vidrio. } \\
\text { Pretratamiento enzimático } 5 \text { : Incubar con búfer de lisis TE }(50 \mathrm{mM} \text { tris- } \mathrm{HCl}, 50 \mathrm{mM} \text { EDTA). } \\
\text { Pretratamiento choque térmico } 3:\left(100{ }^{\circ} \mathrm{C}-\text { nitrógeno líquido) por tres minutos repetidos en ocho ciclos. }\right. \\
\text { Pretratamiento enzimático 6: Proteinasa K-SDS } 1 \mathrm{M} 55^{\circ} \mathrm{C} \text { por cuatro horas. } \\
\text { Extracción: Kit comercial QIA amp DNA Stool de Qiagen. }\end{array}$ \\
\hline Método IX & $\begin{array}{l}\text { Extracción: Kit comercial Stool DNA Isolation de Norgen. } \\
\text { A: Ningún pretratamiento. } \\
\text { B: Pretratamiento choque térmico } 3:\left(100^{\circ} \mathrm{C} \text { - nitrógeno líquido) por tres minutos repetidos en ocho ciclos. }\right.\end{array}$ \\
\hline Método X & $\begin{array}{l}\text { Extracción: Kit comercial QIA amp DNA Stool de Qiagen. } \\
\text { A. Ningún pretratamiento. } \\
\text { B. Pretratamiento choque térmico } 3:\left(100^{\circ} \mathrm{C} \text { - nitrógeno líquido) por tres minutos repetidos en ocho ciclos. }\right.\end{array}$ \\
\hline Método XI ${ }^{(22)}$ & $\begin{array}{l}\text { Pretratamiento choque térmico } 3:\left(100^{\circ} \mathrm{C} \text { - nitrógeno líquido) por tres minutos repetidos en ocho ciclos. }\right. \\
\text { Pretratamiento enzimático } 7 \text { : Búfer de lisis ( } 50 \mathrm{mM} \text { tris- } \mathrm{HCl}, 25 \mathrm{mM} \mathrm{NaCl}, 25 \mathrm{mM} \text { EDTA, } 1 \% \mathrm{SDS}, 100 \mathrm{ug} / \mathrm{mL} \text { de } \\
\text { proteinasa K) incubar a } 56^{\circ} \mathrm{C} \text { por dos horas. } \\
\text { Extracción: In house, fenol - cloroformo - alcohol isoamílico. }\end{array}$ \\
\hline
\end{tabular}


repetitivos de calentamiento (agua a $100^{\circ} \mathrm{C}$ ) y enfriamiento (nitrógeno líquido a $-196{ }^{\circ} \mathrm{C} 0-20{ }^{\circ} \mathrm{C}$ ); enzimáticos, con incubación en diferentes búfer de lisis: búfer 3 , búfer $\mathrm{E}$, búfer tritón, búfer GTP e incubación con proteinasa $\mathrm{K}$ a diferentes tiempos; y mecánicos, con el uso de perlas de vidrio inmersas en búfer de lisis.

Posteriormente a los pretratamientos el aislamiento del ADN se realizó con el uso de kits comerciales, Stool DNA Isolation de Norgen, QIAamp DNA Stool de Qiagen, PureLink Genomic DNA de Invitrogen; y con aplicación del método tradicional de fenol-cloroformo. Las muestras de ADN extraídas fueron almacenadas a $-20^{\circ} \mathrm{C}$.

\section{EXTRACCIÓN DE ADN DE TROFOZOÍTOS}

EI ADN de los trofozoítos fue extraído usando seis métodos de extracción como se observa en la Tabla 2.

Los pretratamientos fueron físicos: choque térmico, con ciclos repetitivos de calentamiento (agua a $100{ }^{\circ} \mathrm{C}$ ) y enfriamiento (nitrógeno líquido a $-196^{\circ} \mathrm{C}$ ); enzimáticos con incubación de búfer de lisis $\mathrm{E}$ a diferentes concentraciones de proteinasa K. Posteriormente, se realizó la extracción con el kit PureLink Genomic DNA de Invitrogen. Las muestras de ADN extraídas fueron almacenadas a $-20^{\circ} \mathrm{C}$.

\section{CUANTIFICACIÓN DE ADN}

La concentración y pureza de las muestras de ADN extraídas se midió mediante espectrofotometría. Las muestras fueron cuantificadas en una lectora EON Gen5 versión 2.04.11 (BioTek), cuyo coeficiente de extinción fue $0,020\left(\mu \mathrm{g} / \mathrm{mL}^{-1} \mathrm{~cm}^{-1}\right.$ y la calidad del ADN se evaluó por la proporción entre las absorbancias $260 \mathrm{~nm} / 280 \mathrm{~nm}$ para cada método.

\section{AMPLIFICACIÓN DEL PCR SEMIANIDADA}

La región del gen glutamato deshidrogenasa (gdh) fue amplificada según Read ${ }^{(16)}$. El método incluye las secuencias de los cebadores Internal Forward Primer GDHiF: CAG TAC AAC TCY GCT CTC GG y Reverse Primer GDHiR: GTT RTC CTT GCA CAT CTC C para el producto del PCR 1, mientras que para el PCR 2 el External Foward Primer fue GDHeF: TCA ACCG TYA AYC GYG GYT TCC GT.

El volumen total de la reacción fue $25 \mu \mathrm{L}$, contenía $1 X \mathrm{PCR}$ búfer con Mg+; 0,2 mM de dNTP; 0,2 $\mu \mathrm{M}$ de cada cebador, $0,1 \mathrm{U} / \mu \mathrm{L}$ de la enzima TAQ HotStart DNA y $3 \mu \mathrm{L}$ de ADN. Las muestras fueron sujetas a una desnaturalización inicial a $94{ }^{\circ} \mathrm{C}$ por tres minutos, seguido de 35 ciclos de desnaturalización a $94{ }^{\circ} \mathrm{C}$ por 30 segundos, hibridación a $56{ }^{\circ} \mathrm{C}$ por 30 segundos y extensión a $72{ }^{\circ} \mathrm{C}$ por un minuto, terminando con una extensión final de a $72^{\circ} \mathrm{C}$ por cinco minutos.

En el caso del gen beta giardina las condiciones de amplificación fueron las descritas por Caccio (17). Los cebadores del PCR 1 fueron el primer forward G7: AAG CCC GAC GAC CTC ACC CGC AGT GC y el primer reverse G759: GAG GCC GCC CTG GAT CTT CGA GAC GAC y el forward para el PCR 2 fue el G376: GAT AAC GAC GCC ATC GCG GCT CTC AGG AA. El volumen total de la reacción y las concentraciones de reactivos fue igual al empleado en el gen gdh. Las muestras fueron sujetas a 35 ciclos $94{ }^{\circ} \mathrm{C}$ por 30 segundos, $65^{\circ} \mathrm{C}$ por 30 segundos y $72{ }^{\circ} \mathrm{C}$ por un minuto con una extensión final a $72{ }^{\circ} \mathrm{C}$ por cinco minutos.

Ambas reacciones fueron realizadas en el Termociclador MultiGene OptiMax Termal Cycler version 1.1. El control negativo fue agua estéril y el control positivo de ADN genómico la cepa Giardia intestinalis (Lambl) Alexeieff (ATCC $尺 30888 D^{\mathrm{TM}}$ ). Los productos del PCR fueron visualizados en geles de agarosa al $2 \%$ teñidos con colorante fluorescente Safe green ABM a $70 \mathrm{~V}$ por 60 minutos.

Tabla 2. Métodos de extracción de ADN de Giardia spp. a partir de trofozoítos.

\begin{tabular}{|c|c|}
\hline Métodos & Descripción \\
\hline Método I & Kit comercial PureLink Genomic DNA de Invitrogen. \\
\hline Método II ${ }^{(7,23)}$ & $\begin{array}{l}\text { Pretratamiento enzimático 8: Incubar con el búfer de lisis E (Tris- } \mathrm{HCl} 100 \mathrm{Mm} \text {, EDTA } 100 \mathrm{mM}, \mathrm{SDS} 2 \%, \mathrm{NaCl} \\
0,2 \mathrm{M} \text {, mercaptoetanol } 1 \mathrm{mM} \text {, proteinasa } \mathrm{K}(100 \mu \mathrm{g} / \mathrm{mL}) \text {. } \\
\text { Extracción: Kit comercial PureLink Genomic DNA de Invitrogen. }\end{array}$ \\
\hline Método III (7) & $\begin{array}{l}\text { Pretratamiento enzimático 9: Incubar con el búfer de lisis E (Tris-HCl } 100 \mathrm{Mm} \text {, EDTA } 100 \mathrm{mM}, \mathrm{SDS} 2 \%, \mathrm{NaCl} \\
0,2 \mathrm{M} \text {, mercaptoetanol } 1 \mathrm{mM} \text {, proteinasa } \mathrm{K}(1 \mathrm{mg} / \mathrm{mL}) \text {. } \\
\text { Extracción: Kit comercial PureLink Genomic DNA de Invitrogen. }\end{array}$ \\
\hline Método IV (7) & $\begin{array}{l}\text { Pretratamiento enzimático 10: Incubar con el búfer de lisis E (Tris-HCl } 100 \text { Mm, EDTA } 100 \text { mM, SDS 2\%, NaCl } \\
0,2 \mathrm{M} \text {, mercaptoetanol } 1 \mathrm{mM} \text {, proteinasa K }(20 \mathrm{mg} / \mathrm{mL}) \text {. } \\
\text { Extracción: Kit comercial PureLink Genomic DNA de Invitrogen. }\end{array}$ \\
\hline Método V (7) & $\begin{array}{l}\text { Pretratamiento enzimático 8: Incubar con el búfer de lisis } \mathrm{E}(\text { Tris- } \mathrm{HCl} 100 \mathrm{Mm} \text {, EDTA } 100 \mathrm{mM}, \text { SDS } 2 \%, \mathrm{NaCl} \\
0,2 \mathrm{M} \text {, mercaptoetanol } 1 \mathrm{mM} \text {, proteinasa } \mathrm{K}(100 \mu \mathrm{g} / \mathrm{mL}) \text {. } \\
\text { Pretratamiento enzimático } 11 \text { : Incubar con proteinasa } \mathrm{K}(20 \mathrm{mg} / \mathrm{mL}) \text {. } \\
\text { Extracción: Kit comercial PureLink Genomic DNA de Invitrogen. }\end{array}$ \\
\hline Método VI & $\begin{array}{l}\text { Pretratamiento choque térmico } 4:\left(100^{\circ} \mathrm{C} \text { - nitrógeno líquido) por cuatro ciclos. }\right. \\
\text { Extracción: Kit comercial PureLink Genomic DNA de Invitrogen. }\end{array}$ \\
\hline
\end{tabular}




\section{ANÁLISIS DE DATOS}

Para evaluar las diferencias en las concentraciones de ADN obtenidas de la cuantificación de los diferentes métodos de extracción se utilizó el análisis de varianza ANOVA con el estadístico HSD Tukey con un intervalo de confianza de $95 \%$ y un valor de $p<0,05$ como estadísticamente significativo. Los datos fueron procesados empleando el software IBM SPSS Statistics para Windows, versión 23 (IBM Corp., Armonk, N.Y., USA).

\section{CONSIDERACIONES ÉTICAS}

La aprobación ética para este estudio fue otorgada por el Comité Institucional de Ética en Investigación (CIEI) del Instituto Nacional de Salud de acuerdo con las normas éticas para la autorización de uso de material biológico para las investigaciones del Centro Nacional de Salud Pública.

\section{RESULTADOS}

\section{EXTRACCIÓN, CUANTIFICACIÓN Y AMPLIFICACIÓN $D E A D N D E$ QUISTES}

Se analizaron 65 muestras de quistes de Giardia spp. con una carga parasitaria promedio de $5 \times 10^{4}$ quistes por muestra, realizando cinco extracciones por método evaluado. Inicialmente, se trabajó con metodologías referenciadas como es el caso de los métodos III, VI, VII, VIII y XI sin obtener resultados satisfactorios; motivo por el que se realizaron modificaciones a las metodologías, proponiendo los métodos I, II, IV, V, IX y X descritos en la Tabla 1.
Los pretratamientos enzimáticos evaluados fueron siete, los que incluían búfer de lisis con detergentes iónicos, como el SDS, no iónicos como el tritón X-100, agentes reductores como el mercaptoetanol, agentes caotrópicos como el tiocianato de guanidina, entre otros, teniendo mejor desempeño el pretratamiento E1 (método I, II y IV) al lograr el éxito en la amplificación del marcador bg (100\% de amplificación). Asimismo, el pretratamiento mecánico con el uso perlas de vidrio en los métodos I y III fue combinado con pretratamientos de choque térmico para ayudar a romper la pared quística logrando la amplificación del marcador bg en $100 \%$ de las muestras.

Con respecto a la concentración de ADN, el método I permitió extraer la mayor cantidad de ácidos nucleicos $(12,24 \mathrm{ng} / \mu \mathrm{L})$, seguido de los métodos $\mathrm{V}$, VII y II $(11,67$; $10,4$ y $8,87 \mathrm{ng} / \mu \mathrm{L})$, cabe resaltar que el método I mostró diferencias significativas comparado a los métodos II $(p=0,039)$, III-IV, VI y IX ( $p<0,001)$. Por otro lado, la pureza del ADN extraído de las muestras fue variable, no encontrando diferencias significativas entre los métodos comparados, mostrando que los 11 métodos evaluados no obtuvieron una calificación de pureza óptima para la relación de absorbancias $A_{260} / A_{280}$, ya que los valores obtenidos estaban entre 1,2 y 1,4 (métodos I-VII y IX), evidenciándose una presencia elevada de compuestos aromáticos; mientras que los métodos VIII, X y XI tenían un rango de 3,09-3,65; lo que indica una alta contaminación con RNA (Tabla 3).

Sin embargo, la variable de interés fue el éxito en la amplificación para evaluar el rendimiento de los métodos,

Tabla 3. Comparación de concentración y calidad de ADN (ng/ $\mu \mathrm{L})$ generados por los diferentes métodos de extracción de ADN de Giardia spp. a partir de quistes.

\begin{tabular}{|c|c|c|c|c|c|c|c|c|c|}
\hline \multirow{2}{*}{$\begin{array}{l}\text { Tipo de } \\
\text { pretratamiento }\end{array}$} & \multirow[t]{2}{*}{ Métodos } & \multicolumn{2}{|c|}{ 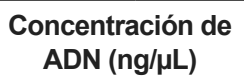 } & \multirow[t]{2}{*}{$\begin{array}{l}\text { Valor } \\
\text { de } p^{*}\end{array}$} & \multicolumn{2}{|c|}{$\begin{array}{l}\text { Calidad de ADN } \\
\qquad\left(A_{260} / A_{280}\right)\end{array}$} & \multirow[t]{2}{*}{$\begin{array}{l}\text { Valor } \\
\text { de } p^{*}\end{array}$} & \multicolumn{2}{|c|}{$\begin{array}{l}\text { Amplificación } \\
\text { bg gdh }\end{array}$} \\
\hline & & Media & DE & & Media & $\mathrm{DE}$ & & $\%$ & $\%$ \\
\hline $\mathrm{M}+\mathrm{ST} 1+\mathrm{E} 1$ & 1 & 12,24 & 1,56 & $<0,001$ & 1,40 & 0,06 & 1,000 & 100 & 60 \\
\hline E1 & II & 8,87 & 3,04 & 0,039 & 1,30 & 0,12 & 0,885 & 100 & 40 \\
\hline $\mathrm{M}+\mathrm{ST} 2$ & III & 4,17 & 0,95 & $<0,001$ & 1,35 & 0,15 & 1,000 & 100 & 0 \\
\hline $\mathrm{ST} 2+\mathrm{E} 1+\mathrm{E} 2$ & IV & 5,28 & 1,26 & $<0,001$ & 1,32 & 0,14 & 0,995 & 100 & 0 \\
\hline $\mathrm{ST} 2+\mathrm{E} 3$ & V & 11,67 & 1,21 & 1,000 & 1,29 & 0,06 & 0,975 & 100 & 0 \\
\hline ST2+E2 & VI & 2,99 & 0,22 & $<0,001$ & 1,20 & 0,21 & 0,409 & 60 & 40 \\
\hline $\mathrm{E} 4+\mathrm{ST} 1$ & VII & 10,40 & 0,90 & 0,831 & 1,39 & 0,07 & 1,000 & 60 & 0 \\
\hline $\mathrm{M}+\mathrm{ST} 3+\mathrm{E} 5+\mathrm{E} 6$ & VIII & 5,87 & 0,43 & SR & 3,09 & 0,45 & SR & 40 & 20 \\
\hline Ninguno & IXA & 4,84 & 1,60 & $<0,001$ & 1,32 & 0,13 & 0,994 & 0 & 0 \\
\hline ST3 & IXB & 6,32 & 1,03 & $<0,001$ & 1,33 & 0,11 & 0,994 & 100 & 20 \\
\hline Ninguno & $X A$ & 4,58 & 0,29 & SR & 3,50 & 0,50 & SR & 20 & 0 \\
\hline ST3 & XB & 4,86 & 0,32 & SR & 3,14 & 0,50 & SR & 60 & 20 \\
\hline $\mathrm{ST} 3+\mathrm{E} 7$ & XI & 96,58 & 3,02 & SR & 3,65 & 0,48 & SR & 0 & 0 \\
\hline
\end{tabular}

ST1:pretratamiento choque térmico 1; ST2: pretratamiento choque térmico 2; ST3: pretratamiento choque térmico 3; E1: pretratamiento enzimático 1; $\mathrm{E} 2$ : pretratamiento enzimático 2; E3: pretratamiento enzimático 3; E4: pretratamiento enzimático 4; E5: pretratamiento enzimático 5; E6: pretratamiento enzimático 6; E7: pretratamiento enzimático 7; ng/ $\mu \mathrm{L}$ : nanogramo por microlitro; $\mathrm{A}_{260} / \mathrm{A}_{280}$ : relación de absorbancias 260 y 280 ; bg: gen de beta giardina; gdh: gen de glutamato deshidrogenasa; DE: desviación estándar; SR: sin resultado de valor de $p$ al haberse excluido del análisis por la baja calidad de ADN.

*Prueba HSD Tukey de la comparación de los métodos evaluados con el método I (mejor rendimiento). 
observando que al realizar la amplificación por PCR semianidada, se evidenció que $100 \%$ de las muestras fueron detectadas con el marcador bg cuando se empleó los métodos I-V, IXB que incluían un pretratamiento con choque térmico, excepto en el método II; y extracción con el kit comercial STOOL DNA Isolation de Norgen, verificado con la visualización de banda de 384 pb (PCR2) en la electroforesis (Figura 1). En el caso del marcador gdh, al aplicar los métodos I,II y VI se logró amplificar entre 40 y $60 \%$ de las muestras, estas metodologías incluían al menos un pretratamiento enzimático y extracción con el kit comercial STOOL DNA Isolation de Norgen verificado con la visualización de banda de 432 pb (PCR2) (Figura 2).

Al evaluar la extracción sin aplicación de pretratamientos a la muestra, se extrajo escasa cantidad de ADN, inferior a 4,8 ng/ $\mathrm{LL}$, siendo el éxito de amplificación mínimo; sólo el $20 \%$ para el marcador bg y nulo para gdh; lo que fue
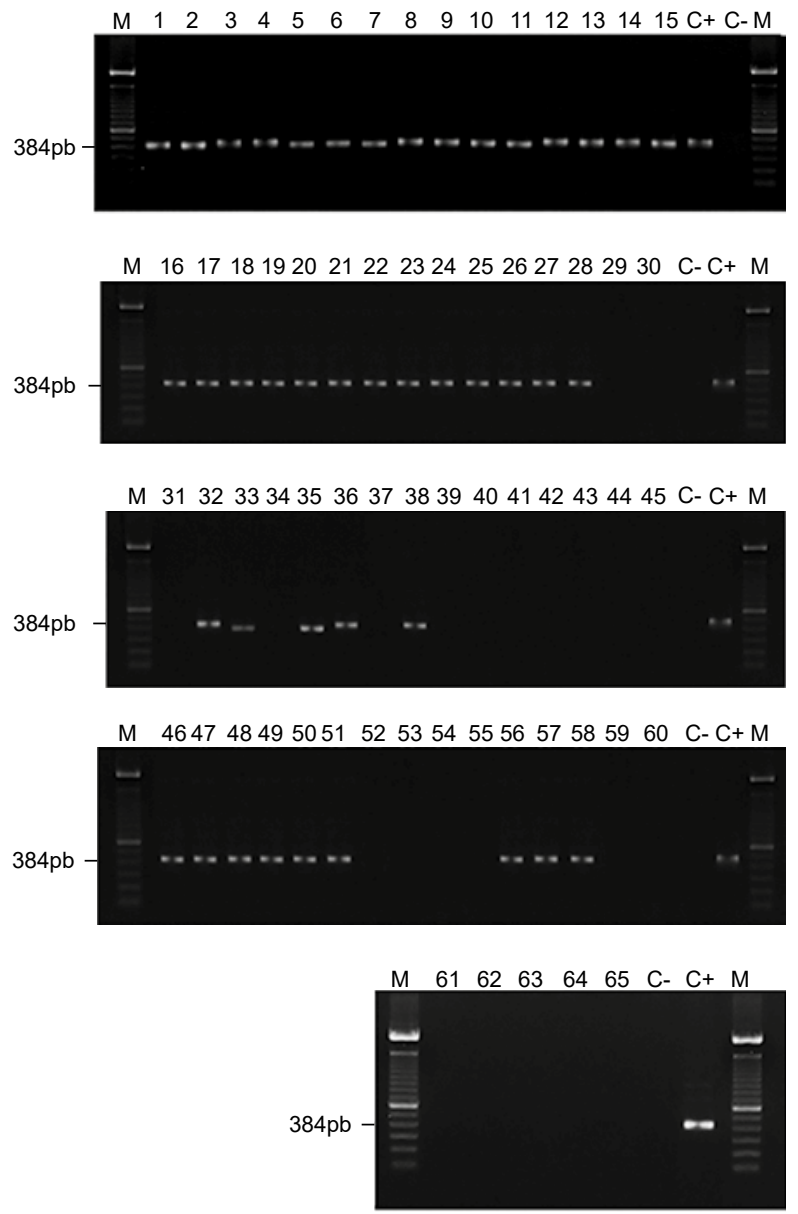

Figura 1. Electroforesis en agarosa al $2 \%$ de productos de PCR semianidada para el gen beta giardina (384 pb) extraído de quistes de Giardia spp.

Línea 1-5 (método I); 6-10 (método II); 11-15 (método III); 16-20 (método IV); 21-25 (método V); 26-30 (método VI); 31-35 (método VII); 36-40 (método VIII); 41-45 (método IXA); 46-50 (método IXB); 51-55 (método XA); 56-60 (método XB); 61-65 (método XI); C+: control positivo; C-: control negativo; M: Marcador de $100 \mathrm{pb}$.

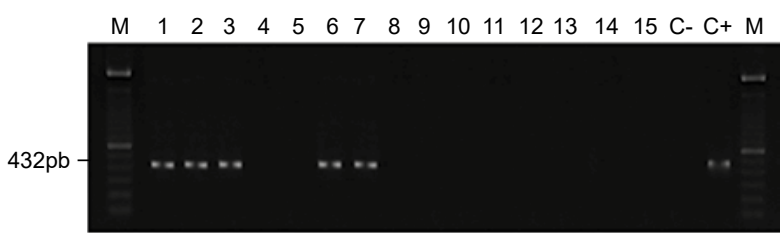

M $161718192021222324252627282930 \quad$ C- C+ M

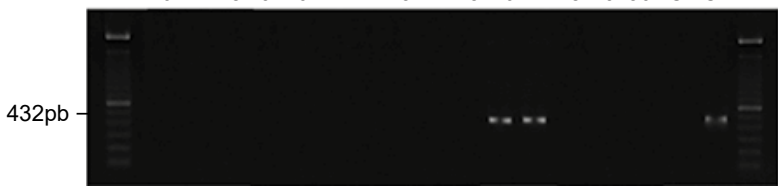

M $3132 \quad 33343536373839404142434445$ C- $C+M$

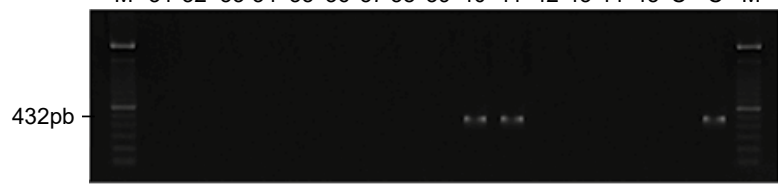

M 464748495051525354555657585960 C- $C+M$ $432 \mathrm{pb}$
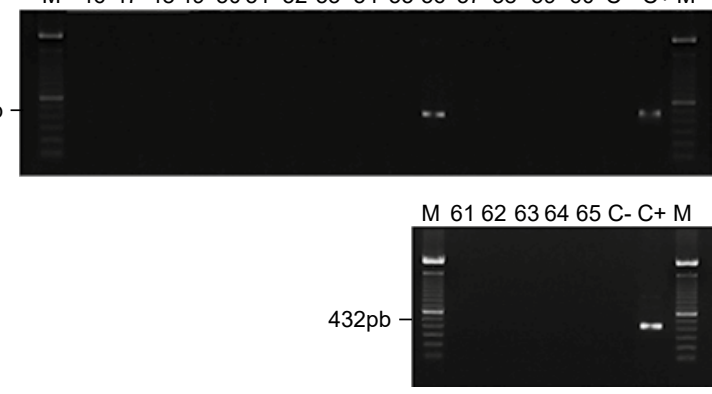

Figura 2. Electroforesis en agarosa al $2 \%$ de productos de PCR semianidada para el gen glutamato deshidrogenasa (432 $\mathrm{pb})$ extraído de quistes de Giardia spp.

Línea 1-5 (método I); 6-10 (método II); 11-15 (método III); 16-20 (método IV); 21-25 (método V); 26-30 (método VI); 31-35 (método VII); 36-40 (método VIII); 41-45 (método IXA); 46-50 (método IXB); 51-55 (método $\mathrm{XA}$ ); 56-60 (método XB); $61-65$ (método $\mathrm{XI}$ ); C+: control positivo; C-: control negativo; M: Marcador de $100 \mathrm{pb}$.

evidenciado en los métodos IXA y XA; cabe resaltar que aplicar un pretratamiento de choque térmico (ST3) mejoró ligeramente los resultados, el kit comercial STOOL DNA Isolation de Norgen mostró mejor rendimiento, mientras que el uso de un método de extracción in house con solventes orgánicos no mostró buen rendimiento.

Los resultados indican que el gen bg presentó alto rendimiento en la detección de ADN parasitario extraído de quiste, amplificando al $100 \%$ de las muestras en al menos seis métodos y presentando mayor intensidad en las bandas de electroforesis (Figura 1); en comparación al marcador gdh, que alcanzó $60 \%$ de detección al emplear el método I, observando bandas más tenues (Figura 2).

\section{EXTRACCIÓN, CUANTIFICACIÓN Y AMPLIFICACIÓN DE ADN DE TROFOZOÍTOS}

Se analizaron muestras de trofozoítos de Giardia intestinalis (ATCC $\AA 30957^{\mathrm{TM}}$ ) con una carga parasitaria promedio de 
Tabla 4. Comparaciones múltiples de acuerdo a la concentración y calidad de ADN generados por los diferentes métodos de extracción de ADN de Giardia spp. a partir de trofozoítos

\begin{tabular}{|c|c|c|c|c|c|c|c|c|}
\hline \multirow{2}{*}{$\begin{array}{l}\text { Tipo de } \\
\text { pretratamiento }\end{array}$} & \multirow{2}{*}{$\begin{array}{l}\text { Métodos } \\
\text { comparados }\end{array}$} & & \multicolumn{2}{|c|}{ 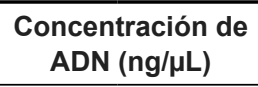 } & \multirow[t]{2}{*}{$\begin{array}{l}\text { Valor } \\
\text { de } p^{*}\end{array}$} & \multicolumn{2}{|c|}{$\begin{array}{c}\text { Calidad de ADN } \\
\left(\mathrm{A}_{260} / \mathrm{A}_{280}\right)\end{array}$} & \multirow[t]{2}{*}{$\begin{array}{l}\text { Valor } \\
\text { de } \mathrm{p}^{*}\end{array}$} \\
\hline & & & Media & $\mathrm{DE}$ & & Media & $\mathrm{DE}$ & \\
\hline \multirow[t]{5}{*}{ Ninguno } & I & II & 4,51 & 2,05 & $<0,001$ & 1,60 & 0,09 & 0,787 \\
\hline & & III & 2,55 & 0,93 & $<0,001$ & 1,83 & 0,17 & 0,998 \\
\hline & & IV & 3,59 & 3,78 & $<0,001$ & 1,76 & 0,41 & 0,989 \\
\hline & & V & 6,93 & 4,68 & $<0,001$ & 1,67 & 0,16 & 0,820 \\
\hline & & VI & 7,37 & 5,24 & $<0,001$ & 1,73 & 0,19 & 0,966 \\
\hline \multirow[t]{5}{*}{ E8 } & II & 1 & 26,56 & 5,73 & $<0,001$ & 1,85 & 0,03 & 0,787 \\
\hline & & III & 2,55 & 0,93 & 0,982 & 1,83 & 0,17 & 0,952 \\
\hline & & IV & 3,59 & 3,78 & 1,000 & 1,76 & 0,41 & 0,983 \\
\hline & & V & 6,93 & 4,68 & 0,937 & 1,67 & 0,16 & 1,000 \\
\hline & & VI & 7,37 & 5,24 & 0,787 & 1,73 & 0,19 & 0,996 \\
\hline \multirow[t]{3}{*}{ E9 } & III & IV & 3,59 & 3,78 & 0,996 & 1,76 & 0,41 & 1,000 \\
\hline & & V & 6,93 & 4,68 & 1,000 & 1,67 & 0,16 & 0,965 \\
\hline & & VI & 7,37 & 5,24 & 0,386 & 1,73 & 0,19 & 0,965 \\
\hline \multirow[t]{2}{*}{ E10 } & IV & V & 6,93 & 4,68 & 0,974 & 1,67 & 0,16 & 0,989 \\
\hline & & VI & 7,37 & 5,24 & 0,687 & 1,73 & 0,19 & 1,000 \\
\hline E8+E11 & V & VI & 7,37 & 5,24 & 0,269 & 1,73 & 0,19 & 0,998 \\
\hline ST4 & VI & 1 & 26,56 & 5,73 & $<0,001$ & 1,85 & 0,03 & 0,787 \\
\hline
\end{tabular}

ST4: pretratamiento choque térmico 4; E8: pretratamiento enzimático 8; E9: pretratamiento enzimático 9; E10: pretratamiento enzimático 10; E11: pretratamiento enzimático $11 ; \mathrm{ng} / \mu \mathrm{L}$ : nanogramo por microlitro; $\mathrm{A}_{260} / \mathrm{A}_{280}$ : relación de absorbancias 260 y 280 ; bg: gen de beta giardina; gdh: gen de glutamato deshidrogenasa; $n$ : número de muestras analizadas; $\mathrm{DE}$ : desviación estándar.

*Prueba HSD Tukey

$5 \times 10^{6}$ trofozoítos por muestra. En relación a la concentración del ADN extraído, según las pruebas de ANOVA y de Tukey existe diferencia significativa entre los métodos evaluados $(p<0,05)$, el método I extrajo mayor cantidad de ADN somático $(26,56 \mathrm{ng} / \mathrm{\mu L} ; \mathrm{p}<0,001)$ comparado a los otros métodos (Tabla 4). Asimismo, en relación a la calidad de las muestras de ADN extraídas, se evidenció que los métodos I y III presentan valores de pureza óptima (relación $A_{260} / A_{280}$ de $1,83-1,85)$ y los métodos II, IV-VI pureza aceptable $(1,60$ $1,76)$. Cabe resaltar que no existió diferencia significativa al comparar la calidad de ADN entre las metodologías. Asimismo, al evaluar los marcadores moleculares ambos presentaron alto rendimiento $100 \%$ de amplificación.

\section{DISCUSIÓN}

En el presente estudio se compararon diferentes metodologías de extracción de ácidos nucleicos de Giardia spp., los resultados de las concentraciones de ADN obtenidas de la fase quística indican que con la aplicación de tres pretratamientos previos a la extracción del kit comercial Stool DNA Isolation de Norgen, descritos en el método I, se puede obtener una concentración de ADN de 12,24 ng/ $\mu \mathrm{L}$ con pureza de 1,4 y lograr un alto rendimiento en la detección molecular de Giardia spp. al usar el marcador bg (100\% de amplificación) y con gdh $(60 \%)$, en comparación a los otros métodos evaluados; cabe resaltar que esta combinación se basó en los métodos de Adamska ${ }^{(19)}$, Rojas ${ }^{(20)}$, Babaei ${ }^{(21)}$ y Molina ${ }^{(24)}$. Con respecto a la evaluación de métodos de extracción de trofozoítos indicamos que al someter a las muestras a pretratamientos (Métodos II-VI) no se logró mejorar la extracción de ADN somático del parásito, más bien se tuvo baja recuperación, contrario a lo reportado por Molina et al. (7), cabe resaltar que en todos los casos la calidad de ADN fue óptima, motivo por el que no se sugiere realizar pretratamientos para este estadio evolutivo de Giardia spp. ya que reduce significativamente la extracción de ADN parasitario.

La tipificación molecular de agentes etiológicos es una prioridad en los laboratorios de salud pública, debido a las implicancias en abordaje terapéutico y distribución epidemiológica; los protocolos de extracción de ácidos nucleicos son variables dependiendo del tipo de muestra y del organismo a estudiar, sobre todo en los parásitos que presentan diferentes estadios evolutivos, por lo que es importante la elección de un método de extracción de alto rendimiento que sea sencillo, rápido y reproducible. Los 
genes de la enzima glutamato deshidrogenasa-gdh ${ }^{(16,25,26)}$ y de la beta giardina-bg ${ }^{(10,17,27)}$ han sido ampliamente usados demostrando gran especificidad para la caracterización molecular de Giardia spp., razón por la que se emplearon para el rendimiento de los métodos evaluados.

La literatura reporta que es necesario separar los quistes de los detritos presentes en las muestras fecales empleando el método de concentración por gradiente de sucrosa de dos fases ${ }^{(12-14)}$, para reducir la posible inhibición de la PCR ocasionada por los componentes de las muestras coprológicas como las sales biliares, proteínas, hemoglobina, lactoferrina, inmunoglobulinas, entre otros ${ }^{(9)}$, y obtener ADN intacto para obtener métodos comparables. Otro punto importante, es eliminar las sustancias derivadas de los procesos de extracción, que según los estudios el uso de columnas procedentes de kits comerciales facilita la purificación de ADN, disminuyendo la presencia de inhibidores químicos, alcanzando mayores tasas de amplificación a las obtenidas empleando una metodología convencional basada en fenol/cloroformo ${ }^{(8,21)}$. En este estudio se evidenció la inhibición de la detección del gen gdh y bg al evaluar los métodos VII y XI (22), cuyo proceso de extracción fue con el método in house, este último método presentó baja calidad de $\operatorname{ADN}\left(3,65\right.$ de relación $\left.A_{260} / A_{280}\right)$ con presencia de alta contaminación.

Por otro lado, al ejecutar los métodos IXA y XA, usando sólo kits comerciales, Stool DNA Isolation de Norgen y el QIAAmp DNASTOOL de Qiagen sin pretratamientos, se encontraron valores promedio de calidad y concentración de ADN de 1,32 / 4,84 ng/ $\mu \mathrm{L}$ y 3,5 / 4,58 ng/ $\mathrm{LL}$, respectivamente, sin éxito en la amplificación para los marcadores estudiados, por lo que es necesario aplicar protocolos de pretratamiento a las muestras. Asimismo, se encontró que realizar un sólo pretratamiento de choque térmico (métodos IXB y XB) resultó insuficiente para lograr la amplificación de más del $20 \%$ del marcador gdh. En concordancia a lo reportado por Sepahvand et al. (18); quienes sugieren el uso de perlas de vidrio, para producir un efecto mecánico y mejorar la eficiencia del protocolo de extracción para recuperar mayor cantidad de ADN. Esto se evaluó al aplicar el método III, recuperando 4,17 ng/uL de ADN logrando una amplificación del $100 \%$ de las muestras para el marcador bg, pero con dificultades para detectar el marcador gdh, motivo por el que se consideró que es importante adicionar algún pretratamiento enzimático para mejorar la recuperación de ácidos nucleicos.

La evaluación del método II, con sólo un pretratamiento enzimático, mostró una concentración de ADN de $8,87 \mathrm{ng} / \mu \mathrm{L}$ y una detección del $100 \%$ del marcador bg y $40 \%$ del gdh; el método IV, incluyó adicionalmente un pretratamiento de choque térmico y degradación enzimática por dos búfer de lisis (E-GTP) y la acción de la proteinasa $\mathrm{K}$, amplificando solo al marcador bg; del mismo modo, se evaluó la acción del búfer tritón y se aplicó el método $\mathrm{V}$ obteniendo resultados similares al método IV.

En la mayoría de estudios previos, no se han mostrado protocolos de extracción con datos específicos de concentración de ADN extraído y resultados de medición por PCR, siendo importante conocer esta correlación. Al realizar el método VI se llevó a cabo la metodología de Adamska et al. (19), quienes realizan pretratamientos de choque térmico (tres ciclos), enzimáticos (proteinasa K) y extracción con kit comercial reportando alta detección del gen bg por PCR. Del mismo modo, Molina et al. (24); informan un $79 \%$ - $80 \%$ de detección molecular por PCR detectando desde 15 quistes/ $\mu \mathrm{L}$, sin embargo, los resultados de este estudio no fueron comparables, alcanzando concentraciones de ADN $<2,9 \mathrm{ng} / \mu \mathrm{L}$ y detección del gen bg sólo en $60 \%$ de las extracciones.

Otras metodologías incluían múltiples pretratamientos enzimáticos (búfer de lisis TE y proteinasa K), mecánicos (con perlas de vidrio) y de choque térmico como lo muestra Babei et al. (22); este protocolo fue evaluado en el método VIII recuperando $5,87 \mathrm{ng} / \mu \mathrm{L}$ de ADN logrando una amplificación de $40 \%$ y $20 \%$ para los marcadores bg y gdh, respectivamente. Este método no fue práctico ya que involucraba muchos pretratamientos de choque térmico (ocho ciclos con nitrógeno líquido) y requería el uso de proteinasa $\mathrm{K}$, que es un insumo costoso. Sin embargo, el pretratamiento mecánico con el uso de perlas de vidrio fue una alternativa adecuada.

En nuestro país, Rojas en $2014{ }^{(20)}$, utilizó dos pretratamientos enzimáticos, el búfer de lisis 3 y el búfer GTP como alternativa al uso de proteinasa $\mathrm{K}$ y extracción con el método convencional reportando alta concentración y pureza de ADN (2156,2 ng/ $\mu \mathrm{L} ; 1,79-2,04)$, pero bajo porcentaje de amplificación al marcador bg (13,3\%). No obstante, al evaluar el método VII no se logró obtener las grandes cantidades de ADN que reportó el autor, a pesar

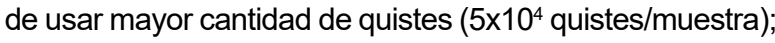
adicionalmente, el porcentaje de amplificación fue de $60 \%$ para el gen bg y nulo para gdh, posiblemente atribuido a la metodología de extracción. En vista de los resultados obtenidos por las investigaciones previas, para aumentar el número de muestras amplificadas se propuso combinar diferentes pretratamientos incluyendo el mecánico, enzimático y de choque térmico.

Una de las limitaciones del estudio fue no incluir mayor número de muestras por cada método evaluado, a fin de mejorar la potencia estadística. Además, al comparar cargas parasitarias de diferentes pacientes existe el sesgo de no homogeneidad en las muestras. No obstante, para disminuir este sesgo se trabajó con la misma cantidad de quistes por método; consideramos que los resultados de este estudio son importantes, ya que evidencian que es posible extraer ADN de la fase quística del parásito a fin de 
llevar futuros estudios de genotipificación de cepas nativas en el país, y es el punto de inicio para determinar límites de detección de Giardia spp. para diferentes marcadores moleculares, y ser utilizados a partir de muestras coprológicas e implementar el diagnóstico molecular de esta parasitosis.

Se concluye que el método que obtiene los mejores resultados para la extracción de ácidos nucleicos a partir de quistes de Giardia spp. incluye la aplicación de tres pretratamientos: mecánicos, enzimáticos y de choque térmico; siendo el marcador molecular bg de mejor rendimiento para el estadio de quiste. Por su parte, el estadio de trofozoíto no requiere pretratamiento. Los resultados de este estudio permiten contar con una metodología reproducible para la detección molecular del parásito Giardia spp. en cualquier estadio evolutivo para posteriores estudios de genotipificación y/o resistencia parasitaria.
Contribuciones de los autores: KTT participó en la concepción, diseño del artículo, análisis e interpretación de resultados. JSM realizó los experimentos y análisis de resultados; SZV participó en la colecta de muestras y realización de base de datos; MBF y EMH participaron en el diseño del artículo e interpretación de resultados. Todos participaron en la redacción del artículo y aprobaron la versión final.

Agradecimientos: Agradecemos a los laboratorios de parasitología de los hospitales nacionales y a los laboratorios de referencia nacional por el apoyo en la realización del presente proyecto.

Fuentes de financiamiento: La presente investigación fue financiada con recursos de Fondo Nacional de Ciencia y tecnología (FONDECYT), Convenio $\mathrm{N}^{\circ}$ 136-2015 proyecto «Caracterización molecular de Giardia spp. y su relación con el perfil de resistencia en hospitales de referencia nacional de Lima-Perú».

Conflictos de interés: Los autores declaran no tener conflicto de intereses en la realización de este trabajo.

\section{REFERENCIAS BIBLIOGRÁFICAS}

1. Adam RD. Biology of Giardia lamblia. Clin Microbiol Rev. 2001;14(3):447-75. doi: 10.1128/CMR.14.3.447-475.2001

2. Alparo I. Giardiasis y desnutrición. Rev Bol Ped 2005;44(3):166-173.

3. Elliot A, Cáceres I. Introducción a la Parasitología Médica del Perú. 3ra ed. Lima: Martegraf; 1994.

4. BoteroD, RestrepoM.Parasitosis Humanas. 5ta edición. Medellín: Corporación para Investigaciones Biológicas; 2012.

5. Miller KM, Sterling CR. Sensitivity of Nested PCR in the Detection of Low Numbers of Giardia lamblia cysts. Appl Environ Microbiol. 2007;73(18): 594950. doi: 10.1128/AEM.00668-07

6. Molina N, Polverino D, Minvielle M, Basualdo J. PCR amplifications of the triosephosphate isomerase gene of Giardia lamblia in formalin-fixed feces. Parasitol Latinoam Microbiol. 2007;49:5-10.

7. Molina N, Polverino D, Minvielle M, Apezteguía M, Aguilar M, Basualdo J. Comparación de métodos de lisis y extracción de ADN de trofozoítos de Giardia lamblia Parasitol Latinoam. 2006;61:133-137. doi: 10.4067/S071777122006000200006

8. Greenspoon S, Scarpetta M, Drayton M, Turek S. QIAamp Spin Columns as a Method of DNA Isolation for Forensic Casework. J Forensic Sci. 1998;43:1024-30.

9. Schrader C, Schielke A, Ellerbroek L, Johne R. PCR inhibitors - occurrence, properties and removal. J Appl
Microbiol. 2012;113:1014-1026. doi: 10.1111/j.1365-2672.2012.05384.x.

10. Rodríguez V, Espinosa O, Carranza J, Duque S, Arévalo A, Clavijo J, Urrea D, Vallejo G. Genotipos de Giardia duodenalis en muestras de niños de las guarderías del Instituto Colombiano de Bienestar Familiar y de perros en Ibagué, Colombia. Biomédica. 2014; 34:271-81. doi: 10.7705/biomedica.v34i2.1713.

11. Polverino, D. Molina, N, Minvielle, M. Lozano, E., Basualdo, J. Técnicas de purificación y ruptura de quistes de Giardia spp. Rev Argent Microbiol. 2006;36(3):97-100.

12. Al-Tukhi $\mathrm{MH}$, Al-Ahdal MN, Peters W. A simple method for excystation of Giardia lamblia cysts. Ann Trop Med Parasitol. 1991;85(4):427-31. doi: 10.1080/00034983.1991.11812587

13. Hautus MA, Kortbee LM, Vetter JC, Laarman JJ. In vitro excystation and subsequent axenic growth of Giardia lamblia. Trans R Soc Trop Med Hyg. 1988;82:858-61. doi: 10.1016/00359203(88)90019-3

14. Tarqui Terrones K, Ramírez Carranza G, Beltrán Fabián, M. Evaluación de métodos de concentración y purificación de Giardia spp. A partir de muestras coprológicas. Rev. Peru Med Exp Salud Publica. 2019;36(2):275-80. doi: http://dx.doi. org/10.17843/rpmesp.2019.362.4151.

15. Keister DB. Axenic culture of Giardia lamblia in TYI-S-33 medium supplemented with bile. Trans R Soc
Trop Med Hyg. 1983;77(4):487-8. doi:10.1016/0035-9203(83)90120-7.

16. Read CM, Monis PT, Thompson RC. Discrimination of all genotypes of Giardia duodenalis at the glutamate dehydrogenase locus using PCR-RFLP. Infect Genet Evol. 2004;4:125-30. doi:10.1016/j.meegid.2004.02.001.

17. Caccio SM, De Giacomo M, Pozio E. Sequence analysis of the beta-giardin gene and development of a polymerase chain reaction-restriction fragment length polymorphism assay to genotype Giardia duodenalis cysts from human faecal samples. Int J Parasitol. 2002;32: 1023-30. https://doi.org/10.1016/ S0020-7519(02)00068-1

18. Sepahvand A, Pestehchian N, Yousefi HA, Gharehbaba RP. Comparison and evaluation of four methods for extracting DNA from Giardia duodenalis cysts for PCR targeting the tpi gene. J Parasit Dis. 2017;41(1):263-7. doi: 10.1007/s12639016-0790-5

19. Adamska M, Leonska-Duniec A, Maciejewska A, Sawczuk M, Skotarczak, B. Comparison of efficiency of various DNA extraction methods from cysts of Giardia intestinalis measured by PCR and TaqMan Real Time PCR. Parasite. 2010;17:299_ 305. doi: 10.1051/parasite/2010174299.

20. Rojas G. Evaluación de tres primeros para la detección molecular de Giardia intestinalis en muestras fecales humanas [Tesis de Licenciatura]. Lima, Perú: Facultad de Medicina, Universidad Nacional Mayor de San Marcos; 2014. 
21. Babaei Z., Oormazdi H., Rezaie S, Rezaeian M, Razmjou E. Giardia intestinalis: DNA extraction approaches to improve PCR results. Exp Parasitol. 2011;128(2):159-62. doi: 10.1016/j. exppara.2011.02.001.

22. Jerez Puebla LE, Núñez FA, Santos LP, Rivero LR, Silva IM, Valdés LA, et al. Molecular analysis of Giardia duodenalis isolates from symptomatic and asymptomatic children from La Habana, Cuba. Parasite Epidemiol Control, 2017;2(3):105-3. doi: 10.1016/j. parepi.2017.05.003.

23. Pelayo L, Fraga J, Núñez Fa, Mendoza D, Torres DR, Finlay CM. Genetic characterization by random amplified polymorphic DNA analysis (RAPD) of 18 isolates of Giardia lamblia obtained from day care children. Exp Parasitol. 2013,104(3-4):162-6. https://doi. org/10.1016/j.exppara.2003.08.003

24. Molina N. Epidemiologia molecular de Giardia lamblia en comunidades urbanas y rurales de Buenos aires y Mendoza, Argentina [Tesis de Magister]. Buenos aires, Argentina: Facultad de Ciencias Exactas, Universidad Nacional de La Plata; 2009.

25. Bertrand I, Albertini L, Schwartzbrod J. Comparison of two target genes for detection and genotyping of Giardia lamblia in human feces by PCR and PCRrestriction fragment length polymorphism. J Clin Microbiol. 2005;43(12):5940-4. doi: 10.1128/JCM.43.12.5940-5944.2005

26. Asher AJ, Waldron LS, Power ML. Evaluation of a PCR protocol for sensitive detection of Giardia intestinalis in human faeces. Parasitol Res. 2012;110(2):8538. doi: 10.1007/s00436-011-2565-3.

27. Uda-Shimoda CF, Colli CM, Pavanelli MF, Falavigna-Guilherme AL, Gomes ML. Simplified protocol for DNA extraction and amplification of 2 molecular markers to detect and type Giardia duodenalis. Diagn Microbiol Infect Dis. 2014;78(1):53-8. doi: 10.1016/j.diagmicrobio.2013.09.008.

Correspondencia: Kathia Mariela Tarqui Terrones.

Dirección: Jirón Cápac Yupanqui 1400, Jesús María, Lima, Perú.

Teléfono: 997033653

Email:kathiax@yahoo.com

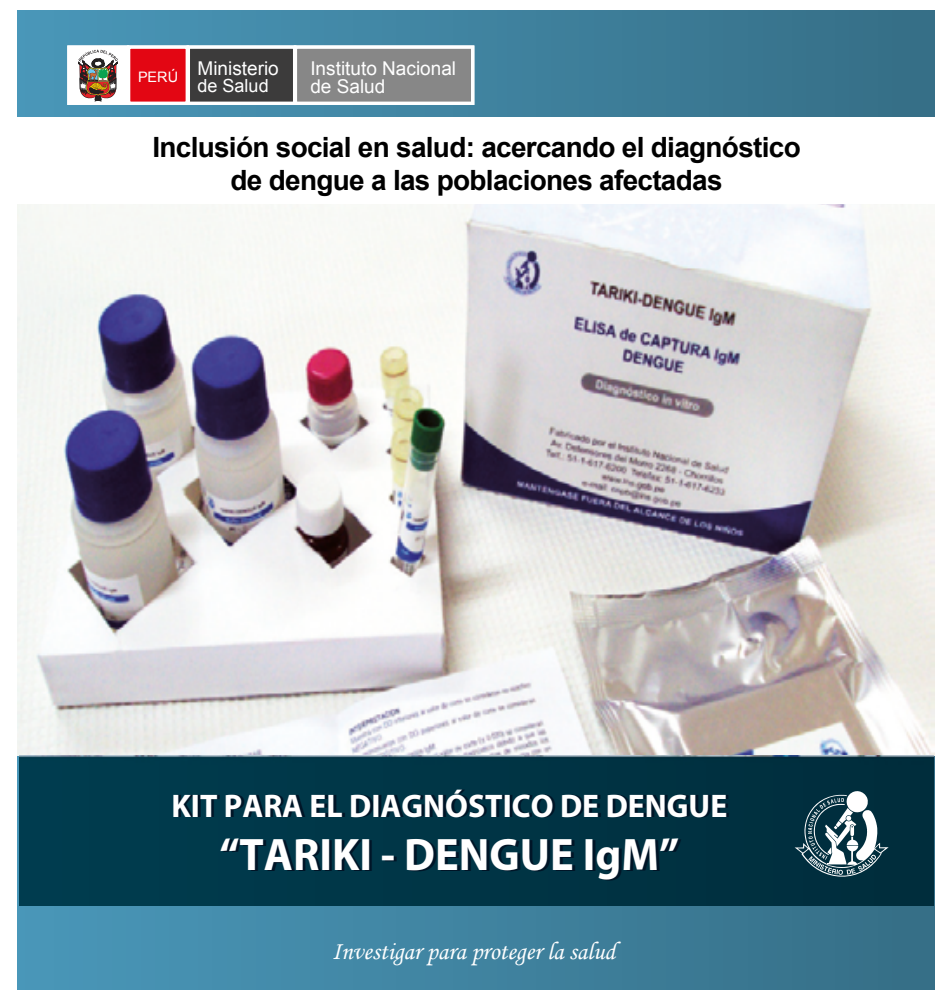

